\title{
OPHTHALMOLOGICAL SOCIETY OP THE UNITED KINGDOM
}

The annual congress was held in the Barnes Hall of the Royal Society of Medicine from March 29 to 31 under the presidency of Mr. Maurice H. Whiting. During his address of welcome to members and guests, the President particularly mentioned four friends from abroad, Professor J. François (Ghent), Dr. John D. Blum (Geneva), Dr. Noëlle Chomé (Lausanne), and Dr. P. Mendoza (Philippine Islands).

\section{Presidential AdDress}

If members were to be offered the chance to decide in advance what kind of a presidential address they would prefer, a large number of practising ophthalmologists would undoubtedly reply: " Let the President tell us about some subject which concerns the average clinician, and let that subject be something directly experienced by the President over a long period". Mr. Whiting fully satisfied this conjectural precept; his subject "The Surgical Treatment of Rodent Ulcers near the Eye" has interested him for many years, and he was able to range over a long series of cases observed in person and carefully documented.

He put forward a plea for surgical rather than radiational treatment in a majority of rodent ulcers near the eye. Admittedly there are certain infiltrating types which demand irradiation, but excision is the method of choice in most cases. One serious objection to ray-therapy is that damage may thereby be inflicted upon the eye and its lacrimal apparatus. So far as the cosmetic end-result is concerned there is little to choose between the two methods, but provided that the cases are judiciously selected, surgery is a more reliable means of eradicating these insidious neoplasms.

\section{BOWMAN LECTURE}

Twenty years ago a beautiful demonstration of Sir Henry Dale's work was arranged at Mount Vernon for the benefit of the O.S.U.K. Already his reputation was world-wide, and since then he has broken new ground and won fresh honours. On this occasion, Sir Henry, as Bowman lecturer, paid tribute to the outstanding achievements of Bowman.

In his lecture on "The Eye as a Physiological Reagent", Sir Henry emphasized that pharmacological facts gleaned from a field so limited in size as the eye and its adnexa were nevertheless applicable to the whole body. Alterations in the pupillary diameter, changes in the tone of orbital muscle, and retraction of the nictitating membrane were accessible to direct scrutiny, and all these phenomena, together with their modifications under the influence of drugs, could be recorded by means of experimental devices, such as rotating drums. Many mysteries still 
remained to be unravelled concerning the pharmacological action of substances upon the eye, but progress was constantly being made, and a number of apparent discrepancies had been resolved by the discovery that myoneural junctions are not real structures distinct from nerve-endings. The myoneural junction was merely a hypothetical concept of earlier physiologists, who had not yet discovered the significance of acetylcholine.

\section{Other CONTRIBUtions}

Dr. John P. Blum (Geneva) gave an interesting account of observations made by Professor A. Franceschetti, Dr. F. Bamatter, and himself upon the ocular symptoms and signs in Still's disease; this formed a valuable prelude to the main discussion on "The Association of Ocular and Articular Disease". Mr. L. H. Savin and Mr. A. B. Nutt gave a preliminary survey, and were followed by Professor G. W. Pickering, Dr. F. Dudley Hart, and Professor E. J. Wayne. Encouraging results from the use of cortisone and ACTH were mentioned, but each speaker insisted upon the limitations, dangers, and uncertainties of these new preparations, and the need for careful selection of cases.

Professor J. François described a case of scleromalacia perforans associated with arthritis deformans and pemphigus. Dr. Macdonald Critchley gave a paper on "Types of Visual Perseveration". On the afternoon set aside for pictorial case demonstrations followed by discussion under the chairmanship of Mr. A. B. Nutt (Vice-President of the Society), the President described uniocular retrobulbar neuritis arising as a complication of measles in a six-year-old girl. One evening was devoted to a series of surgical films. Professor François showed his cataract operations, and other films were provided by Mr. F. A. Williamson-Noble, Mr. H. B. Stallard, Mr. B. W. Rycroft, Mr. P. Jameson Evans, and jointly by Miss Jean Dollar and Miss Mary Savory.

An exhibition of instruments and books was on view at the Cowdray Hall throughout the congress. 